The Influence of Friction upon the Generation of a Voltaic Current

This content has been downloaded from IOPscience. Please scroll down to see the full text. 1880 Proc. Phys. Soc. London 41

(http://iopscience.iop.org/1478-7814/4/1/302)

View the table of contents for this issue, or go to the journal homepage for more

Download details:

IP Address: 128.192.114.19

This content was downloaded on 01/10/2015 at 03:21

Please note that terms and conditions apply. 


\title{
PROCEEDINGS
}

ov

\section{THE PHYSICAL SOCIETY}

\author{
OF LONDON.
}

AUGUST 1880.

\section{The Influence of Friction upon the Generation of a Voltaic Current. By Shelford Bidweld, M.A.*}

IN 'Nature' of March 4th Prof. Barrett calls attention to the fact (which I believe had been ubserved before) that the electro-motograph, or receiving-instrument of Edison's loud-speaking telephone, is capable of generating an electric current. He considers that we have here a new source of electricity, the current generated being due to the motion of a chalk cylinder under a metallic surface. His chalk, he adds in a note, had been impregnated some months before with a solution of phosphate of soda, but was, when used, practically dry.

The construction of the motograph is essentially as follows:- One end of an arm of brass is joined to the diaphragm of the instrument; the other end, which is faced with platinum, is pressed by a spring against the upper surface of a horizontal chalk cylinder. This cylinder is mounted on a thick brass core or spindle, and can be made to rotate and rub against the platinum on the arm by turning a winch-handle. The cylinder is impregnated with certain chemical substances, of which I believe caustic potash is always one, though it is not mentioned by Prof. Barrett.

- Read March 13, 1880.

VOL. IV, 


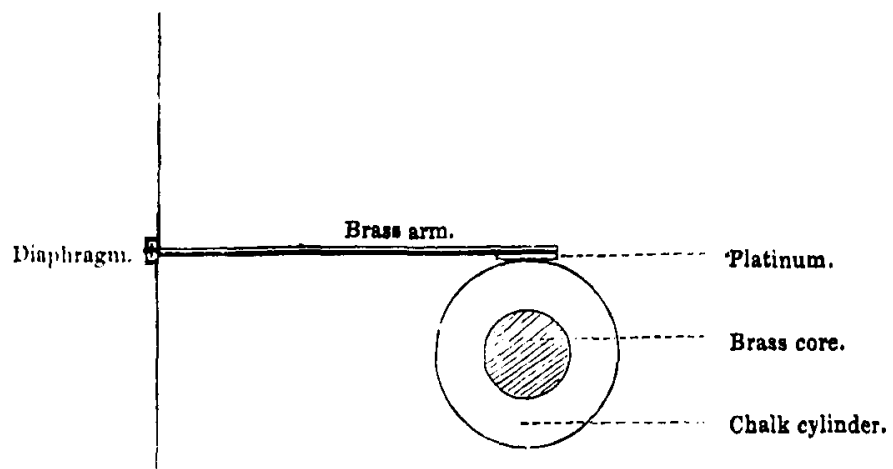

It will be seen that there are here two metals, brass and platinum, connected by a medium containing caustic potash; and the arrangement looks so much like a voltaic couple that I was not surprised, on connecting the brass and platinum to a galvanometor, to find a small + current flowing from the platinum-faced arm. The cylinder was not rotated, and had not been moistened for some months. On turning the handle the galvanometer at once indicated a much stronger + current passing from the platinum. The effect of the friction was to greatly increase the strength of the current.

I then faced the brass arm with zinc instead of platinum. On connecting the instrument to the galvanometer a small deflection was again observed; but this time the + current flowed, as I expected, not from the zinc-faced arm, but from the brass core of the cylinder. The substitution of the zinc for the platinum bad the effect of reversing the current, brass being positive to platinum and negative to zinc. In this case too, rotation of the cylinder largely increased the current.

I now laid aside the motograph, and connected to the two wires of the galvanometer a sheet of brass and a sheet of platinum. Between these metallic plates I placed a thin slice of dry chalk; the galvanometer indicated nothing. I rubbed the metals successively against the chalk; still the galvanometer remained motionless. For the pure chalk 1 substituted a chalk plate which had been soaked in a saturated solution of phosphate of soda and thoroughly dried; again there was no result. Neither was there when I used dry blotting-paper which had been saturated with phosphate of soda. But with 
a piece of blotting-paper which had been saturated with a solution of caustic potash and made as dry as possible, the results were just the same as with the electro-motograph : brass and platinum gave a + current from the platinum; hrass and zinc gave a + current from the brass; and in both cases the current was much increased by rubbing.

This experiment was repeated with the following pairs of metals-brass and platinum, zinc and lead, zinc and copper, lead and copper, tin and copper, zinc and tin-covering one of every pair of metals successively with a wet cloth and rubbing the one so covered with the other. In every case the friction seemed to considerably increase the current which was generated on mere contact. If, for instance, a piece of lead is covered with a wet cloth and a piece of copper is pressed upon it, a + current will of course flow from the copper. On rubbing, this current is very greatly increased. If the copper be the metal covered, and the lead rubbed against it, the current from the copper will again be greatly increased, but apparently not quite so much so as in the former case. And I believo that this difference in the effect produced according to the matal covered, occurs in the case of all the other pairs of metals which I tried. In some cases it is very notable; in others it is small, and extremely difficult to detect without a machine for producing uniform friction. But, as far as I can judge, the effect on the current is always greatest when the positive element is covered and the negabive element exposed to friction.

It seems, therefore, that Prof. Barrett's experiment is only an illustration of the effect of friction on one of the elements of a voltaic couple in increasing the current. This effect is, however, so very remarkable that $I$ was induced to make further experiments.

The most curious result at which $I$ arrived is this:-Take two plates of the same metal, cut from the same sheet, and connect them with a galvanometer; cover one of them with a wet cloth and bring the other down upon it. If the two pieces of metal are in the same physical condition there will be no material deflection of the galvanometer. Now rub the covered metal with the bare metal. As long as the rubbing continues, the galvanometer indicates a current of electricity, 
which ceases as soon as the rubbing is stopped. And this current invariably flows from the plate which is covered by the wet cloth.

I have made the experiment with plates of tin, lend, copper, brass, and zinc, with the same result in every case.

I do not suggest an explanation of the above-mentioned phenomena. When the two plates of a single metal are used, it appears that friction renders the one rubled relatively electro-positive. But in tho case of two metals, friction seems generally to have a greater effect upon the negative than the positive element, and it makes the negative elcment not more positive but more negative. Any possible explanation that occurs to me of the one case is inconsistent with the other.

Certain speculations led me to try the effect of passing a battery-current through a pair of metallic plates, separated by a piece of wet rag or paper, while they were being rubbed tncrether; and I found that when the current passed from the covered to the uncovered plate, a remarkable diminution in the friction occurred. A current in the opposite direction produced no such result. I exhibit a little apparatus for rendering this effect visible to a large audience.

This experiment scems to show conclusirely that the generally received theory of electrolytic action is sufticient to explain the phenomena presented by the electro-motograph; for it is difficult to conceive any other possible effect of the current than the liberation of hydrogen on the surface of the plate which is connected with the negative pole of the battery, the laver of hydrogen having the effect of diminishing the friction.

Rirerstone Iodge, Wandsworth, S.W.

II. On some Effects of Yitratory Motion in Fluids; on the Attraction che to the Flow of Liquids from an Eapanded Orifice; and Laboratory Notes. By R. H. Ridout.

On some Effects of Vibratory Motion in Fluids. $\mathrm{ON}_{\mathrm{N}}$ causing a stream of coal-gas to bubble through a liquid contained in a flask, it may by careful adjustment be made to issue from a suitable jet in an oscillatory manner, in the plane which would contain a sensitive flame issuing from 